\title{
Pencegahan Bullying dalam Pendidikan Anak Usia Dini
}

\author{
Despa Ayuni \\ Pendidikan Islam Anak Usia Dini, STIT AI-Quraniyah Manna
}

$\triangle$ Corresponding author

(despaayuni@gmail.com)

\begin{abstract}
Abstrak
Bullying merupakan masalah yang serius bagi anak-anak, karena bullying dapat memberikan efek negatif bagi anak yang menjadi korban bullying seperti rendahnya harga diri, kecemasan yang berlebihan dan depresi. Pada usia dini menjadi salah satu periode yang mendasar dalam mencegah dan menghentikan bullying. Banyak penelitian terbaru menunjukkan bahwa bullying terjadi pada anak usia dini. Jenis-jenis bullying pada anak usia dini adalah fisik, verbal dan relasional. Sebagai guru dalam pendidikan anak usia dini hendaknya memberikan lingkungan yang aman dan nyaman pada anak dalam mencegah bullying saat ini. Tujuan dari peninjauan ini adalah untuk menyajikan bukti empiris tentang bullying pada anak usia dini, karakteristik anak yang terlibat dalam bullying, impilikasi guru dalam mencegah bullying, dan program pencegahan bullying pada anak usia dini.
\end{abstract}

Kata Kunci: Anak Usia Dini, Bullying; Bullying Anak Usia Dini; Pencegahan Bullying; Pendidikan Anak Usia Dini

\begin{abstract}
Bullying is a serious problem for children, because bullying can have negative effects on children who are victims of bullying such as low self-esteem, excessive anxiety and depression. Early childhood becomes one of the fundamental periods in preventing and stopping bullying. Many recent studies have shown that bullying occurs in early childhood. The types of bullying in early childhood are physical, verbal and relational. As teachers in early childhood education, they should provide a safe and comfortable environment for children in preventing bullying today. The purpose of this review is to present empirical evidence on bullying in early childhood, the characteristics of children who are involved in bullying, the implications of teachers in preventing bullying, and programs to prevent bullying in early childhood..
\end{abstract}

Keywords: Early Childhood, Bullying; Early Childhood Bullying; Bullying Prevention; Early childhood education programs

\section{PENDAHULUAN}

Pendidikan anak usia dini merupakan salah satu penyelenggaraan pendidikan yang dapat memberikan stimulasi pertumbuhan dan perkembangan pada anak usia dini seperti, fisik, kecerdasan, sosial emosional, kognitif, bahasa dan komunikasi. (Fakhrudin, 2010; Partini, 2010; Suyadi, 2010; Sujiono, 2013). Pada pertumbuhan dan perkembangan anak usia dini terdapat beberapa masa yang secara langsung dan tidak langsung memperngaruhi seorang pendidik ketika menghadapi anak usia dini, seperti masa peka anak, masa egosentris, masa meniru, masa pembangkang yang terjadi pada anak, masa eksplorasi dan masa berkelompok (Sujiono 3013).

Pada masa berkelompok anak-anak masih mengalami kesulitan dan permasalahan sosial dan emosional, sehingga anak dapat berperilaku bullying. Bullying merupakan perilaku yang negatif terhadap satu anak atau lebih yang dilakukan secara berulang-ulang (Olweus, 1993). Sedangkan menurut Storey \& Slaby (2013) bullying adalah bentuk pelecehan emosional atau 
fisik yang dilakukan oleh anak seperti disengaja dengan cara melukai seseorang, diulang sering menargetkan korban yang sama berulang kali, dan ketidakseimbangan kekuasan seperti memilih korban yang dipandang lebih lemah dari pelaku bullying. Bullying yang dimaksudkan adalah memukul, mendorong, mengancam, menganggu teman, mengatakan hal yang tidak baik, mengejek, menyentuh secara tidak sopan, merampas, menghina penampilan seseorang dan lainlain (Morrison, 2016).

Hasil survei terbaru yang ditemukan Hinitz, Shore dan Kumara (2010) bahwa 48,78\% dari 123 guru Taman Kanak-kanak di Sleman Yogyakrarta melaporkan bahwa mereka memiliki anak yang menjadi korban perilaku agresif, seperti agresi verbal $88,62 \%$ terdapat anak yang menggoda temannya, 34,92\% terdapat anak yang mengatakan hal buruk dengan temannya, dan $16,26 \%$ penganggu membungkam teman mereka. Agresivitas terhadap orang lain, 45,53\% mengambil paksa barang milik teman, $17,89 \%$ menghancurkan barang, $50,41 \%$ anak menyembunyikan barang milik temannya. Agresivitas fisik yang dilakukan anak seperti $34,15 \%$ menarik rambut teman, $73,17 \%$ memukul teman, $19,51 \%$ menggigit teman dan $63,41 \%$ mnendang teman. Agresivitas fisiologis $64,23 \%$ tidak mengizinkan seorang teman untuk bergabung dengan grup dan 60,16\% tidak mengizinkn seorang teman untuk duduk di dekat mereka. Dari data yang ditunjukkan bahwa fenomena intimidasi sering terjadi di Taman Kanakkanak, sehingga anak memiliki perilaku negatif yang disebut bullying.

Pentingnya guru mengenali gejala awal bullying pada anak usia dini. Karena penelitian terbaru menunjukkan bahwa perilaku bullying sering terjadi pada anak usia dini (Alsaker \& Gutzwiller-Helfenfinger, 2010; Alsaker \& Nägele, 2008; Kirves \& Sajaniemi, 2012; Monks \& Smith, 2010). Terlihat bahwa semakin banyak bukti yang menunjukkan tentang bullying pada tahun awal yang terjadi pada anak usia tiga tahun hingga tujuh tahun dan sedikit yang mengetahui tentang bullying pada usia ini (Reunamo, et al., 2014).

Kirves dan Sajaniemi (2012) menjelaskan bahwa terdapat 12,6\% anak usia dini berusia tiga hingga enam tahun terlibat langsung bullying. Jumlah rata-rata bullying di tempat penitipan anak adalah 1,3 . Terdapat $2,2 \%$ anak yang terlibat dalam bullying yang dikategorikan sebagai pelaku bullying, dan $39,1 \%$ banyak anak yang menjadi korban bully adalah anak-anak berkebutuhan khusus.

Para guru di lingkungan anak usia dini sering kali mengabaikan bullying. Guru-guru berpikir bahwa itu perilaku biasa yang dilakukan oleh anak dan bukan perilaku yang disengaja untuk menyakiti anak-anak lain. Sehingga guru mengabaikan perilaku dan mengatakan ?anakanak akan menjadi anak-anak" atau dianggap normal sebagai gurauan, hal ini disebabkan guru gagal melihat bullying karena tidak adanya pengawasan yang memadai dan guru gagal memahami bahwa perilaku awal ?pra-bullying" akan berubah menjadi bullying seterusnya (Storey \& Slaby, 2013; Morrison, 2016).

Pengamatan juga dilakukan di salah satu taman kanak-kanak yang berada di Kabupaten Rejang Lebong Bengkulu, Indonesia. Terlihat bahwa guru-guru tersebut belum mengetahui gejala awal bully. Terlihat anak yang berkebutuhan khusus diganggu oleh temannya seperti dipukul tanpa sebab, diganggu ketika pembelajaran, mengatakan hal yang buruk ?kamu bau", tidak diperbolehkan bermain dengan teman yang lain. Tetapi guru yang berada di taman kanakkanak tersebut hanya menegur pelaku bullying tanpa memberikan penjelasan bahwa perilaku itu tidak baik, sehingga anak yang menjadi korban bully tidak mendapatkan perlindungan.

Penyebab dari kejadian tersebut adalah guru belum mengetahui dan tidak dapat mencegah gejala awal bullying. Hal ini disebabkan karena guru kurang mendapatkan informasi mengenai bullying, kurangnya diskusi antar guru tentang bullying, dan guru tidak memiliki pengetahuan yang cukup tentang bullying sebagai fenomena yang berkembang pada saat ini (Kirves, L \& Sajaniemi, N., 2012).

Pentingnya seorang guru mengenali tanda-tanda awal bullying untuk mencegah perkembangan tersebut, karena penindasan yang terjadi dapat menyebabkan masalah hubungan di kemudian hari, baik bagi pelaku bullying atau korban bullying (Kirves, L \& Sajaniemi, N., 2012). Terdapat minat yang tumbuh baik secara nasional atau internasional untuk mencegah 
perkembangan bullying yang terjadi pada masa kanak-kanak (Repo, L., 2015). Beberapa tahun terakhir, sebuah badan penelitian yang sudah berkembang menunjukkan bahwa asal-usul bullying terletak pada masa kanak-kanak dan mulai berkembangnya pratik pencegahan bullying secara khusus dalam lingkungan pendidikan anak usia dini (Vlachou, Botosoglou, \& Andreou, 2013; Lee, Smith, \& Monks, 2011; Monks, 2011; Monks \& Smith, 2010; Alsaker \& Nägele, 2008; Perren \& Alsaker, 2006; Alsaker \& Valkanover, 2001). Makalah ini dibuat untuk mencegah berkembangnya bullying dalam pendidikan anak usia dini, dengan membedakan karakteristik anak yang menjadi korban bullying dan pelaku korban bullying, implikasi guru, dan program pencegahan bullying dalam pendidikan anak usia dini.

\section{METODE PENELITIAN}

Metode yang digunakan adalah studi literatur. Studi literatur adalah bagian terpenting dalam metode ilmiah (Wahyudin, 2017). Dengan menelaah beberapa jurnal yang terkait dengan bullying dalam pendidikan anak usia dini.

\section{HASIL DAN PEMBAHASAN}

\section{Bullying Anak Usia Dini}

Penelitian terbaru menunjukan bahwa bullying terjadi pada anak usia dini. Perilaku bullying yang terjadi pada anak usia dini adalah menggertak orang lain untuk mendapatkan perhatian, mendapatkan apa yang mereka inginkan (makanan, mainan, pakaian, dan lain-lain), memanggil nama teman dengan menggunakan kata-kata yang tidak baik (Huston, J., \& Bailey, S. J, 2008).

Bullying anak usia dini diukur dengan menggunakan strategi observasi, kuantitatif, atau kualitatif, didapatkan tiga jenis bullying yang terjadi pada anak usia dini, yaitu fisik, verbal dan relasional (Jansen et al., 2012; Gültekin-Akduman, 2012; Özdemir \& Tepeli, 2015; Rose et al., 2016). Bullying fisik pada anak usia dini adalah Mengigit, menendang, mencubit, mendorong, memukul, meludah, meninju, melempar dengan benda, dan menarik rambut teman. Bullying verbal yang dilakukan anak usia dini adalah mengancam, menggoda, menertawakan temannya, memanggil nama yang tidak baik, mengancam, menggunakan kata-kata yang tidak baik, mempermalukan, dan suka bergosip. Bullying relasional dengan mengajak temannya untuk tidak bermain dengan seseorang, merusak mainan teman, menolak anak lain untuk bergabung, mencegah berberapa anak bermain atau berbicara dengan orang lain, mengabaikan beberapa teman.

\section{Karakteristik Korban Bullying, Pelaku Bullying, dan Pengamat Bullying}

Terjadinya intimidasi karena pembentukan sosial, terdapat anak-anak yang menggertak, anak-anak yang menjadi korban bullying, dan pengamat bullying (Storey \& Slaby, 2013). Pelaku bullying biasanya membentuk sebuah kelompok dan mencari sasaran bullying. Anak yang menjadi sasaran perlaku bullying adalah anak yang tunduk, diam, mudah menyerah, dan mudah menangis sehingga anak yang menjadi sasaran bullying bagi pelaku sudah mencapai kesuksesan dan anak tersebut menjadi target terus menerus. Pengamat bullying adalah anak-anak yang menonton kejadian tersebut. Pengamat bullying melihat siapa yang menjadi korban dan perilaku bullying, biasanya anak pengamat bullying akan menjadi takut pada pelaku, menjauhi anak yang menjadi korban, dan secara pasif mereka menerima perlaku bullying. Kemungkinan anak pengamat bullying tertarik untuk bergabung dengan pelaku bullying.

Bagi seorang guru penting untuk mengenali karakteristik dari korban bullying pelaku bullying, dan pengamat bullying. Hal ini dilakukan agar guru bisa melihat gejala awal bullying dan melakukan intervensi untuk mencegah dan menghentikan perilaku bullying yang terjadi di sekolah. Berikut ini karakteristik dari pelaku bullying, korban bullying, dan pengamat bullying (Storey \& Slaby, 2013).

Pelaku bullying dalam lingkungan anak usia dini adalah menggunakan agresi fisik (mencubit, memukul, menendang, mendorong dan melempar benda) atau melakukan agresi 
verbal (mengatakan hal buruk, berteriak, mengejek, mengancam, dan lain-lain) suka mengambil, menyembunyikan, menghancurkan mainan favorit korban. Melakukan agresi relasional dengan cara mengabaikan atau menjelekan korban dengan orang lain agar tidak berteman, menyebarkan cerita kebohongan, dan mengucilkan korban dengan orang lain.

Korban bullying memiliki karakteristik seperti pemalu dan kurang pengalaman secara sosial dengan teman-teman lain. Dalam situasi sosial korban bullying tidak bisa membaca situasi sehinga mereja sering diperlakukan buru dan dijauhi oleh teman-teman. Korban bullying cenderung tunduk dan tidak tegas ketika mengatakan ?tidak" atau ?hentikan" mereka cenderung pasrah dan tidak mengenali bahwa mereka sedang ditindas. Korban bullying cenderung menyendiri ketika bermain, tidak memiliki keterampilan berteman atau menjadi pempimpin, lemah, merasa tidak aman, sensitif, tertekan sehingga tidak ingin pergi sekolah, memiliki harga diri yang rendah, dan kesulitan dalam hubungan sosial.

Pengamat bullying pada anak usia dini hanya menonton kejadian tersebut. Pengamat bullying mengamati perilaku yang dilakukan oleh pelaku terhadap korban tanpa membantu korban sama sekali. Hal ini disebabkan ketika mereka membantu akan menjadi korban bullying selanjutnya. Efek dari pengamat bullying adalah mereka tidak bisa melakukan apapun untuk membantu korban, sehingga pengamat bullying akan memiliki rasa bersalah dikemudian hari.

Tabel 1 menjelasakan perbandingan karakteristik korban bullying dan pelaku bullying yang terjadi pada anak (Olweus, 1993).

Tabel 1. Karakteristik Pelaku Bullying dan Korban Bullying

\begin{tabular}{|l|l|}
\hline \multicolumn{1}{|c|}{ Pelaku Bullying } & \multicolumn{1}{c|}{ Korban Bullying } \\
\hline $\begin{array}{l}\text { Memiliki kemampuan yang kuat mengendalikan } \\
\text { dan menekan orang lain. }\end{array}$ & $\begin{array}{l}\text { Memiliki rasa hati-hati, pendiam, peka, malu, dan } \\
\text { menjadi penarik perhatian pelaku }\end{array}$ \\
\hline Tidak sabar dan mudah marah & $\begin{array}{l}\text { Mudah cemas, merasa tidak aman, dan mudah } \\
\text { menangis }\end{array}$ \\
\hline $\begin{array}{l}\text { Pemberontak dan agresif terhadap orang lain baik } \\
\text { orang tua maupun guru }\end{array}$ & Harga diri rendah \\
\hline $\begin{array}{l}\text { Tidak perduli atau tidak memiliki rasa empati } \\
\text { terhadap korban }\end{array}$ & Mudah berkecil hati \\
\hline $\begin{array}{l}\text { Memiliki fisik yang kuat dari teman-temannya } \\
\text { Suka menganggu teman }\end{array}$ & $\begin{array}{l}\text { Memiliki sedikit teman } \\
\text { teman-teman sebaya }\end{array}$ \\
\hline $\begin{array}{l}\text { Menggunakan kekerasan fisik seperti memukul, } \\
\text { mendang, dan lain-lain. }\end{array}$ & \begin{tabular}{l} 
Memiliki fisik yang lemah dari teman-teman. \\
\hline
\end{tabular} \\
\hline
\end{tabular}

Penelitian yang dilakukan oleh Splete (2005) menemukan bahwa anak-anak yang cenderung menjadi pelaku bullying adalah anak-anak yang sering menonton televisi, sehingga mereka mengalami penurunan stimulasi kognitif. Karakteristik lain pada anak yang menjadi pelaku bullying adalah memiliki perilaku agresif, kurang memiliki keterampilan sosial, dan menemukan bahwa pelaku bullying lebih memiliki banyak teman dan memiliki keterampilan kepemimpinan yang baik dengan teman-temannya (Perren \& Alsker, 2005). Penelitian yang dilakukan Tanrikulu (2018) menemukan bahwa karakteristik pelaku bullying berdasarkan kesepakatan guru adalah anak laki-laki, anak yang memiliki masalah perilaku, mempunyai keterampilan kepemimpinan, dan anak yang mampu memgungkapkan perasaan. 
Karakteristik anak yang menjadi korban bullying pada anak Taman Kanak-kanak adalah anak cenderung terisolasi, tundu, lebih menutup diri, dan tidak memiliki teman bermain (Perren \& Alsker, 2005). Berbeda dengan peneltian yang dilakukan Tanrikulu (2018) mengungkapkan hasil bahwa guru sepakat yang menjadi korban bullying adalah anak perempuan atau anak lakilaki, anak yang mengikuti aturan, anak yang mampu mengungkapkan perasaan, dan anak yang memiliki komunikasi yang baik.

\section{Implikasi Guru Mencegah Bullying Anak Usia Dini}

Implikasi guru dalam mencegah bullying dalam pendididikan anak usia dini sangatlah penting. Hal yang dapat dilakukan guru ketika melihat terjadinya bullying di kelas (Morrison, 2016; Morrison, 2012): 1) Guru dapat berbicara kepada anak secara pribadi dan kelompok ketika melihat anak terlibat dalam perilaku bullying. Guru dapat mengatakan kepada anak seperti ?putra, menurutmu apa yang dirasakan fatih ketika kamu memukulnya sampai dia menangis?" 2) Guru dapat menghalangi jika melihat anak yang ingin membully anak lainnya. Dengan cara mengalihkan perhatian anak dengan mengajak anak bermain bersama. 3) Guru tetap waspada melihat tanda-tanda perilaku bullying di dalam kelas dan lakukan intervensi dengan cepat ketika muncul tanda-tanda bullying. 4) Guru dapat mengajarkan nilai-nilai moral yang baik pada anak, seperti berperilaku kooperatif, bekerja sama, menghargai sesama teman, dan lain-lain. 5) Guru dapat memberikan tugas kelompok kepada anak agar anak dapat bekerja sama, kemudian guru meminta anak menceritakan tugas tersebut. 6) Guru dapat buatlah suasana kelas menjadi nyaman dan hangat, agar anak merasa disambut dengan baik. 7) Ajaklah orang tua untuk berkolaborasi dan berdiskusi untuk mencegah dan menghentikan bullying agar kelas bebas dari perilaku tersebut. 8) Buatlah pertemuan antara orang tua dengan menghadirkan pihak-pihak yang mengerti dan paham tentang bullying yang terjadi pada anak usia dini. Agar orang tua mengetahui tanda-tanda bullying dan cara mengatasi bullying. 9) Guru harus memiliki pemahaman tentang perilaku bullying. Jika guru tidak memiliki pehamaman dan hanya diam saja tanpa tindakan, maka guru tidak melaksanakan kewajiban dalam melindungi anak usia dini. 10) Guru dapat mengajarkan metode ?katakan, hindari, dan laporkan" kepada anak dengan cara bermain peran di dalam kelas [?katakan": ajarkan anak untuk membela diri secara verbal ketika menjadi korban bullying seperti ?jangan ganggu aku" atau ?aku tidak takut dengan kamu". Mintalah anak untuk mengatakan dengan tenang dan tegas ketika bermain peran. ?hindari" : minta anak untuk menghindar, dan bukan lari ketika dalam kondisi tersebut. Jika anak lari, pelaku bullying akan mencari korban-korban lainnya. ?llaporkan" : ajarkan anak untuk melaporkan kejadian bullying jika dilakukan secara berulang-ulang, sehingga guru dapat mengambil langkah yang tepat dalam menghentikan dan mencegah bullying di dalam kelas. 11) Guru tetap memberikan informasi kepada orang tua tentang kekerasan yang terjadi di sekolah. Jika anak mereka menjadi pelaku atau korban ajaklah mereka untuk mengatasi masalah tersebut bersama-sama. 12) Guru dapat membacakan buku tentang bullying. Membacakan buku dapat dilakukan di kegiatan awal, inti dan akhir pembelajaran. Selain membacakan buku cerita, guru dapat memutarkan video tentang bullying.

\section{Program Pencegahan Bullying dalam Pendidikan Anak Usia Dini}

Program yang dapat dilakukan dalam pencegahan bullying di Taman kanak-kanak adalah Program Bernese Against Victimization yang dibuat oleh Alsaker (2012). Program ini dirancang untuk mengembangkan dan mempertahakan kemampuan guru dalam mencegah perilaku bullying dan mencegah pembohongan. Be-Prox dikembangkan pada tahun 1998 untuk program sekolah dalam mencegah bullying di TK dan Sekolah Dasar.

Program dibuat selama empat bulan, terdapat enam sesi dan memberikan tugas kepada guru ketika pertemuan dilaksanakan. Dalam pelaksanaan pertama memberikan informasi mengenai bullying pada anak, manfaat pencegahan, sehingga guru dapat berdiskusi. Terdapat enam modul Be-Prox (Tabel 2). 
Tabel 2 Program Bernese Against Victimization di TK dan Sekolah Dasar

\begin{tabular}{|c|c|}
\hline Modul & Tujuan \\
\hline $\begin{array}{c}\text { Modul 1 Sensitisasi ? ?Sikap } \\
\text { Subjektif" }\end{array}$ & $\begin{array}{c}\text { Kepekaan guru dalam menyikapi bullying. Guru didorong untuk } \\
\text { menyikapi terjadinya bullying. Guru diminta untuk memberikan } \\
\text { informasi kepada orang tua tentang mencegah dan mengatasi } \\
\text { bullying. }\end{array}$ \\
\hline $\begin{array}{c}\text { Modul 2 mendeteksi bullying: } \\
\text { ?lihat itu" }\end{array}$ & $\begin{array}{c}\text { Guru mengamati perilaku anak secara sistematis. Guru dapat } \\
\text { mendokumentasikan kejadian tersebut atau menggunakan kuesioner } \\
\text { yang telah yang diberikan pada kegiatan program. }\end{array}$ \\
\hline $\begin{array}{c}\text { Modul 3 aturan hening: ?3ari } \\
\text { kita bicara bersama tentang } \\
\text { bullying dan viktiminasi" }\end{array}$ & $\begin{array}{c}\text { Menyadarkan anak-anak bahwa perilaku bullying tidak baik } \\
\text { dilakukan dengan cara lembut untuk mengatasinya. }\end{array}$ \\
\hline $\begin{array}{c}\text { Modul 4 aturan melawan } \\
\text { bullying:" kontrak" }\end{array}$ & $\begin{array}{c}\text { Guru dan anak membuat persetujuan atau kontrak ketika dalam } \\
\text { kelas. Mendiskusikan kepada anak aturan yang baik dan tidak baik. }\end{array}$ \\
\hline $\begin{array}{c}\text { Modul 5 Ambil tindakan } \\
\text { ?Penggunaan positif dan } \\
\text { negatif sanksi" }\end{array}$ & $\begin{array}{c}\text { Agar guru mengambil tindakan secara sistematis dan konsisten } \\
\text { menggunakan sanksi positif dan negatif jika melanggar kontrak yang } \\
\text { telah dibuat bersama. }\end{array}$ \\
\hline $\begin{array}{c}\text { Modul 6 Mengembangkan } \\
\text { kompetensi sosial }\end{array}$ & $\begin{array}{c}\text { Guru diminta agar memberitahukan kepada anak bahwa perilaku } \\
\text { bultig harus di berhentikan dan melaporkan tndakan tersebut kepada } \\
\text { guru dan orang tua. Guru diminta untuk mengajarkan anak untuk } \\
\text { membedakan antara pelaku dan korban bullying. }\end{array}$ \\
\hline
\end{tabular}

Alsker \& Valkanover (2012)

Penelitian Ambarani, Indrariani, \& Zahraini (2018) membuat lima tahap kegiatan dalam program anti bullying yang terintegrasi untuk anak usia dini. Penelitian dilakukan di Semarang yang melibatkan enam belas orang guru pendidikan anak usia dini. Tahap program anti bullying yang terintegrasi dengan anak usia dini yaitu : 1) Tahap Penyampaian Materi. Materi yang disampaikan dalam tahap ini adalah tingkatan, keseriusan dan dinamika bullying yang sedang berkembang, mengenali seawal mungkin perilaku bullying, strategi dalam pencegahan bullying, memberikan pengetahuan kepada anak mengenali dan merespon secara efektif perilaku bullying, memberikan pengetahuan bahwa bullying merupakan perilaku yang tidak baik, memberikan intervensi untuk mencegah bullying, antisipasi dampak bullying dari segi kesehatan, dan teknik penyusunan RPP tentang bullying. 2) Tahap Pelatihan. Guru diminta untuk menyusun RPP tentang bullying dan di terapkan dalam latihan peer teaching. 3) Tahap Praktik Peer Teaching. Setiap guru melakukan praktik pembelajaran bullying dengan rekan mereka sendiri. RPP yang telah dibuat guru dipraktikkan dalam peer teaching. Teknik pembimbing dan pendamping dilakukan untuk melihat tingkat pemahaman guru terhadap penerapan RPP yang telah dibuat dalam tema bullying. 4) Tahap Praktik Classroom Practice. Tahap ini merupakan kelanjutan dari tahap sebelumnya. Guru mempraktikan ke sekolah mereka sendiri. 5) Tahap Diskusi dan Refleksi Diri. Tahap akhir ini adalah guru mendiskusikan dan refleksi diri tentang kelebihan dan kekurangan dari pelatihan dan pengembangan pembelajaran pencegahan bullying

\section{SIMPULAN}

Bullying dapat terjadi di mana pun dan kapanpun. Penelitian terbaru menunjukkan perilaku bullying terjadi pada masa kanak-kanak awal yang berusia tiga tahun hingga tujuh tahun dan yang mengetahui gejala awal pada anak usia dini hanya sedikit. Bullying pada anak usia dini terdapat tiga jenis yaitu fisik, verbal, dan relasional. Jika perilaku bullying tidak dicegah atau dihentikan maka akan berdampak buruk pada anak, maka dari itu pentingnya seorang guru mengenali gejala awal bullying pada anak usia dini untuk mencegah dan mengentikan bullying. Pencegahan yang dapat dilakukan seorang guru dalam pendidikan anak usia dini adalah mengetahi karakteristik anak yang terlibat dalam bullying. Karakteristik dari pelaku bullying seperti mampu mengendalikan, menekan orang lain, tidak sabaran dan mudah marah, memiliki sifat yang agresif, tidak ada rasa empati, memiliki fisik yang kuat, suka menganggu teman. 
Sedangkan korba bullying memiliki rasa hati-ati, pendiam, pemalu, kurang bersosialisasi, mudah menangis, mudah cemas, memiliki harga diri yang rendah, berkecil hati, dan memiliki fisik yang berbeda dengan pelaku bullying. Keterlibatan guru sangat penting dalam mencegah bullying pada anak usia dini. Hal yang dapat dilakukan oleh guru ketika melihat terjadinya bullying di dalam kelas adalah melakukan menanyakan perasan anak yang terlibat bullying, mengalihkan perhatian anak yang ingin membully, melakukan intervensi dengan cepat ketika muncul tandatanda bullying, mengajarkan nilai-nilai moral dan agama kepada anak, membuat susanan kelas yang nyaman dan hangat, mendiskusikan bersama orang tua dalam mencegah bullying dengan menghadirkan pihak-pihak yang paham tentang bullying, guru memilki pemahaman tentang bullying, ajak anak bermain peran dengan mengajarkan metode ?katakan, hindari, dan laporkan" ketika menjadi korban bullying, memberikan informasi kepada orang tua jika terjadi bullying di dalam kelas, dan membacakan buku cerita atau video tentang bullying pada anak. Program pencegahan bullying menjadi faktor penting dalam anak usia dini, program yang dapat dilakukan dalam pencegahan bullying adalah Program Bernese Against Victimization yang dibuat oleh Alsaker (2012). Program ini dirancang untuk mengembangkan dan mempertahakan kemampuan guru dalam mencegah perilaku bullying. Serta penelitian Ambarani, Indrariani, \& Zahraini (2018) membuat lima tahap kegiatan dalam program anti bullying yang terintegrasi untuk anak usia dini yaitu tahap penyampaian materi, tahap pelatihan, tahap pelatihan peer-teaching, tahap classroom practice, tahap diskusi dan refleksi diri. Bullying dapat dicegah dan dihentikan dalam pendidikan anak usia dini karena hasil penelitian menunjukkan bahwa bullying dapat dicegah dalam kontek sosial atau lingkungan sekolah dengan memberikan intervensi pada anak yang terlibat (Bradshaw et al., 2009).

\section{DAFTAR PUSTAKA}

Hinitz, B., Shore, M., \& Kumara, A. (2010). Making Anti-Bullying Research a Part of Early Childohood Classroom Practice in Comparative International Contexts: The United States and Indonesia. AFRA.

Storey, K., \& Slaby, R. (2013). Eyes on Bullying in Early Childhood. USA: Education Development Center.

Olweus, D. (1997). Bully / Victim Problems in School: Facts and Intervention. European Journal of Psychology of Education, XII (4), 495-510.

Kirves, L., \& Sajaniemi, N. (2012). Bullying in Early Educational Settings. Early Child Development and Care, 182 (3-4), 383-400. http://dx.doi.org/10.1080/03004430.2011.646724

Repo, L. (2015). Bullying and Its Prevention in Early Childhood Education. Helsinki: University of Helsinki. ISBN 978-951-51-0200-3, ISSN 1799-2508.

Vlachou, M., Botsoglou, K., \& Andreou, E. (2013). Assessing bully/victim Problems in preschool children: A multimethod approach. Journal of Criminology, 8 pages. Article ID 301658

Lee, S.-H., Smith, P. K., \& Monks, C. (2011). Perception of bullying-like phenomena in South Korea: A qualitative approach from a lifespan perspective. Journal of Aggression, Conflict and Peace Research, 3, 210-221.

Monks, C., \& Smith, P. K. (2010). Peer, self and teacher nominations of participant roles taken in victimization by five- and eight-years-old. Journal of Aggression, Conflict and Peace Research 2(4), 4-14

Alsaker, F., \& Nägele, C. (2008). Bullying in kindergarten and prevention. In D. Pepler \& W. Craig (Eds.), Understanding and addressing bullying: An international perspective, 230-252. Bloomington, IN: Bloomington.

Alsaker, F. D., \& Valkanover, S. (2001). Early diagnosis and prevention of victimization in kindergarten. In J. Juvonen \& S. Graham (Eds.), Peer harassment in school: The plight of the vulnerable and victimized. New York, NY: Guilford Press.

Perren, S., \& Alsaker, F. (2006). Social behavior and peer relationships of victims, bully-victims, and bullies in kindergarten. Journal of Child Psychology and Psychiatry, 47, 45-57. 
Alsaker, F., \& Gutzwiller-Helfenfinger, E. (2010). Social behavior and peer relationships of victims, bully-victims and bullies in kindergarten. In S. R. Jimerson, S. M. Swearer, \& D. L. Espelage (Eds.), Handbook of bullying in schools: An international perspective (pp. 87-100). New York, NY: Routledge.

Reunamo, J., Kalliomaa, M., Repo, L., Salminen, E., Lee., H-C., \& Wang, L-C. (2014).Children?] Strategies in Addressing Bullying Situations in Day Care and Preschool. Early Child $\begin{array}{llll}\text { Development } & \text { and } & \text { Care } & \text { 952-967. }\end{array}$ http://dx.doi.org/10.1080/03004430.2014.973871

Wahyudin, S.T. (2017). Statistika Ekonomi Konsep, Teori dan Penerapan. Malang: Ub Press.

Tanrikulu, I. (2018). Teacher reports on early childhood bullying: how often, who, what, when and where. Early Child Development and Care, 1-13. doi:10.1080/03004430.2018.1479404

Ambarini, R., Indrariani, E. A., \& Zahraniani, A. D. (2018). Antisipasi Pencegahan Bullying Sedini Mungkin: Program Anti Bullying Terintegrasi untuk Anak Usia Dini. Journal of Dedictors Community UNISNU Jepara, 2 (2), p-ISSN 2548-8783

Splete, H. (2005, October). Preschool environment predicts grade school bullying. Pediatric News, 39 (10), $33 . \quad$ Retrieved from http://go.galegroup.com.ezproxy. stthomas.edu/ps/i.do?id=GALE\%7CA138141213\&v=2.1\&u=clic_stthomas\&it=r $\& p=I T O F \& s w=w$

Huston, J., \& Bailey, S.J. (2008). Children and Bullying: A Guide For Parents. Monata State University

Gültekin-Akduman, G. (2012). Okul öncesi dönemde akran zorbaliğının incelenmesi. Journal of Society \& Social Work, 23(1), 121-137

Jansen, P. W., Verlinden, M., Dommisse-van Berkel, A., Mieloo, C., van der Ende, J., Veenstra, R., ... Tiemeier, H. (2012). Prevalence of bullying and victimization among children in early elementary school: Do family and school neighbourhood socioeconomic status matter? BMC Public Health, 12(1), 145.

Özdemir, S., \& Tepeli, K. (2015). Okul öncesi çocuklarda görülen fiziksel ve ilişkisel saldırganlık davranışlarının incelenmesi. Uluslararası Avrasya Sosyal Bilimler Dergisi, 6(18), 229245.

Bradshaw, C. P., \& Johnson, R. M. (2011). The social context of bullying and peer victimization: An introduction to the special issue source. Journal of School Violence, 10(2), 107-114. 